\title{
Study on the Construction of the Teaching Resources Platform based on Cloud Computing
}

\author{
He Pan , Taihao Li* \\ Information technology teaching and Management Center \\ Jilin Agricultural University \\ Changchun,,China \\ panhe@jlau.edu.cn; lth@jlau.edu.cn
}

\begin{abstract}
Cloud computing is the development direction of the IT industry in the future and the application of cloud computing is bound to exert a profound influence on the field of higher education. The construction of the network educational resources platform in universities is to integrate all sorts of educational resources of universities and it can provide rapid and convenient resource storage, sharing, learning and computing services. This paper studies the current situation of domestic and foreign cloud computing education, proposes the strategy of constructing information resource libraries in universities under the environment of cloud computing, and studies how to construct the network educational resources platform in institutions of higher learning under the cloud model.
\end{abstract}

Key words- resource platform; cloud computing; cloud education

\section{INTRODUCTION}

The development of computer and information technology triggers a great upsurge in educational informationization worldwide and also brings an unprecedented influence to the higher education of China. After the year of 2009, cloud computing entered the field of education. The "cloud computing teaching resources platform" that takes promoting the "socialized service of low-carbon education" and collaborative learning as the core idea has rapidly become the frontier of educational informationization and educational technology application,

which causes in-depth research and discussion among the experts in the field of education [1-2]. How to popularize and apply this new means of education in the teaching practice and make use of "cloud computing" service to construct a teaching resources platform for the use of teaching and effectively improve the teaching quality has become a major problem faced by the broadest masses of educational technology workers [3].

\section{CLOUD EDUCATION}

The educational application of cloud computing started in 2007 when Google and IBM jointly launched the "cloud computing" plan to provide a safe could platform to rapidly transfer teaching resources for the use of students and help teachers timely follow up the relevant information such as scores of students. Multiple institutions of higher learning took an active part in the plan, including Carnegie Mellon University, Stanford University and Massachusetts Institute of Technology. In the British Westminster University, 96\% students use Gmail to receive and send message and share information [4]. In addition, Gmail is also correlated to Google Calendar, Google Talk and Google Doc. When using the software in the platform, users can also share information with Gmail. In the Arizona State University of the USA, 65,000 university students use Gmail. The Graham Primary School in North Carolina, USA makes the virtual computer desktop by connecting to the cloud computing service of Siemon Company and provides students with courses, assignments and other learning materials. In May 2009, China Association for Educational Technology held the first national "advanced training of cloud computing assisted teaching” in Shanghai, which officially led cloud computing to China's educational field. Professor Li Jiahou of Shanghai University proposed the concept of "cloud computing assisted teaching" and pointed out that the cloud computing assisted teaching meant that schools and teachers make use of the services provided by "cloud computing" to establish an informationized environment of personalized teaching, support the teaching of teachers and the learning of students, and improve the teaching quality.

It is found during the research process that foreign countries attached importance to the cloud computing education earlier than China. China started to study and think about how to apply the cloud computing platform to education only after 2008. The relevant cases and the document literature of scholars for the following years since then indicate that considerable achievements has been made in China through various attempts and exploration.

As the central government advances the digitalization process of educational resources in recent years, Chinese scholars from all works of life have developed and made such digital resources as quality course library, network course library, courseware, animation, and material library of test questions [5]. However, the scholars did not fully consider the universality and compatibility of different teaching platforms when designing and developing such teaching resources. As a result, numerous teaching resources cannot be shared and used effectively, thus causing the waste of educational resources and the loss of value. Besides, most of the existing teaching platforms adopt the $\mathrm{B} / \mathrm{S}$ network structure's centralized access to teaching resources. When the user visits for the same period of time are saturated, it is likely to cause network congestion and unsmooth communication between client and server and 
consequently visitors cannot extract the teaching resources they need. At present, students mainly study the network resources on their own, and there is a lack of teachers' guidance and interaction between teachers and students, which severely influences the teaching effect and teaching quality. As to the said problems, this study attempts to seek a reasonable service system of co-constructing and sharing digital resources to deal with the isolation, repetition, low quality and difficult-to-share issues of digital resources.

With respect to the co-construction and sharing of teaching and learning resources, cloud computing has the most obvious advantage. It can upload the isolated educational resources via Internet to store in the cloud server, and its management and safety work is handled by the professional technical team of the cloud service provider. Besides, it adopts the unified data standards and unified database system to realize the sharing and unified management of educational resources. Users can have access to the educational resources they need only by having terminal equipment that can connect to the network. Meanwhile, they can also share their resources with others, thus realizing the openness and sharing of educational resources. In this way, the existing problems of educational resources such as low degree of resource sharing, lack of communication and collaboration as well as uneven resource distribution can all be effectively addressed.

\section{CONSTRUCtion OF ResOURCES ClOUdS}

Resource sharing is the core of cloud computing which can facilitate the construction of various resources, and various cloud-based platforms can be constructed, but the most fundamental is to construct the following resources clouds.

\section{A. Learning Resources Cloud}

As the learning resources of various institutions of higher learning are relatively independent, they cannot be allocated and used effectively, which leads to the increase in learning cost. The construction of learning resources cloud can not only realize the effective allocation and reasonable use of the learning resources of institutions of higher learning, but reduces the learning cost and improves the teaching quality. Courses are integral parts of learning resources cloud, especially the highly operable courses. Students can not only acquire operating skills and experience in the virtualized environment, but increase their learning interest by having the feeling of being personally on the scene. The virtualized classroom teaching also enables students to rapidly master the operating skills through constant exploration. After the virtualization of the learning resources, various services can be provided for distance educational institutions and users.

\section{B. Teacher Resources Cloud}

The communication among teachers in institutions of higher learning is weak and the allocation of teacher resources is not balanced. The Ministry of Education asks each institution of higher learning to establish a mechanism of building a team of both full-time and part-time teachers so as to ensure the quantity and quality of front-line part-time teachers and strengthen the training of their teaching abilities. The institutions of higher learning can construct teacher resources cloud to strengthen the mobility of the front-line part-time teachers between institutions of higher learning and enterprises, realize the sharing of quality teacher resources, promote the quality construction of teachers having qualifications of dual professional degrees, advance the diversification of the teaching staff of institutions of higher learning, and enhance the communication, connection and cooperation between educational circles and business circles.

\section{Digital Library Cloud}

The library construction is an important indicator for measuring institutions of higher learning, but the repeated construction of libraries is serious in various institutions of higher learning. The use of cloud server provides cloud storage for the libraries and facilitates the management of library digital resources. With the digital library cloud, institutions of higher learning have no need to buy a large number of servers, set up the mirror images of various digital resource libraries, and buy and install all kinds of platform software, which greatly reduces the expenses of operation and maintenance. Cloud computing brings a brand-new change to the libraries of institutions of higher learning, and the management mode of libraries is no longer the traditional hardware management but the virtual cloud management.

\section{CONCLUSION}

As the cloud computing technology and application mode are increasingly mature, cloud service has become an important way for the future Internet development. As a brand-new service mode, cloud computing is gradually entering every field of people's daily life. China's educational field is now taking this as the opportunity to deepen the reform and innovation and actively explore and promote its extensive application to education. The use of cloud computing in the network education is the manifestation of the brand-new education mode, and the teaching resources platform based on "cloud computing" will play a huge role in the foreseeable future. The "cloud computing” application mode greatly integrates educational resources, strengthens the functional development of "cloud computing" teaching resources platform, and promotes the sustainable and healthy development of various educational resources in China. The wide platform provided by cloud computing can not only offset the adverse factors existing in China's education system, but also address the problems such as how to increase the use efficiency and sharing of educational resources and reasonably allocate educational resources, as well as the relevant support service for education.

\section{ACKNOWLEDGMENT}

Subject of the Twelfth Five-year Plan for Science of Education in Jilin Province: 《Research and Implementation 
of Teaching Resouces Sharing System on Cloud Computing from data center 》 (GH13181)

[1] Chen Hui, Strategies Research on Using Educational Technology to Promote Higher Education Resources Equity [D]. Hunan: Central South University, 2009:1-58[1].

[2] Fu Yufan. Campus Starts “the Journey of Cloud” [J]. China Education Network, 2011 (2):19-20.

[3] Li Jiahou. Move towards the Educational Technology - "Cloud" [J] Distance Education Journal, 2008 (3)

[4] Zhao Zongjin, Li Dan. Low-cost and Efficient Recommendation Work by Multi-campus Cooperation - A discussion on the free open source framework of Gmail [J]. Document, Information \& Knowledge, 2012, 04: 124-128.

[5] Zhang Ze'ang, Wu Jiawei. A Study on Cloud-computing-based Education Platform [J]. China Distance Education, 2010 (06): 66-69, 80 